\title{
Quality by Design: Impact of Product Variables and Their Interaction on the Particle Size in Lyophilization of Sodium Fluoride
}

\author{
V. K. Mourya1, Yogesh Choudhari', Mangeshkumar Padame ${ }^{2 *}$ \\ ${ }^{1}$ Government College of Pharmacy, Aurangabad, India \\ ${ }^{2}$ Government College of Pharmacy, Amravati, India \\ Email:vkmourya@gmail.com,yogeshpharm@gmail.com, "mangesh.pharma@gmail.com
}

Received 19 May 2015; accepted 26 January 2016; published 29 January 2016

Copyright $@ 2016$ by authors and Scientific Research Publishing Inc.

This work is licensed under the Creative Commons Attribution International License (CC BY).

http://creativecommons.org/licenses/by/4.0/

\section{(c) (i) Open Access}

\section{Abstract}

The aim of present study was to use QbD approaches to evaluate the effect of independent product variables and their interaction on particle size of sodium fluoride and then obtain the optimized experimental condition for predefined particle size of sodium fluoride. The sodium fluoride is mainly used in dental preparation for delivering the fluoride ion to the tooth enamel for that nano-particle size is required. Nowadays the milling process is used to reduce the particle size. But that process has some limitations due to crystalline nature of sodium fluoride; for overcoming those limitations, lyophilization method is used. A $4^{3}$ level full factorial design was used to study the significant influence of process and product variables i.e. 1) Concentration of sodium fluoride, 2) Concentration of PVP, 3) Sample volume, 4) Drying surface, on particle size of sodium fluoride. The experimental design result shows that independent product variables significantly modify the structure and improve particle size reduction of sodium fluoride.

\section{Keywords}

QbD, PAT, Lyophilization, Particle Size

\section{Introduction}

Sodium fluoride is important API in oral care, and it is mainly used in prevention of tooth decay and dental car-

${ }^{*}$ Corresponding author.

How to cite this paper: Mourya, V.K., Choudhari, Y. and Padame, M. (2016) Quality by Design: Impact of Product Variables and Their Interaction on the Particle Size in Lyophilization of Sodium Fluoride. Soft Nanoscience Letters, 6, 1-10.

http://dx.doi.org/10.4236/snl.2016.61001 
ries. The action of sodium fluoride is depending upon how it delivered the fluoride ion to tooth enamel, for that minimum particle size is required. For achieving the required minimum particle size nowadays milling process is used. But milling process has some limitations to produce homogeneous particle size because of crystalline nature of sodium fluoride. For overcoming the problem of nature of sodium fluoride, the lyophilization process is used to obtain the desired particle size. Lyophilization is a drying process which is widely used to develop the powders with improved solubility properties

The application of quality by design (QbD) [1] on Lyophilization for particle size reduction of sodium fluoride is giving opportunity to set the goal and obtain the predetermined product quality. For implementation of $\mathrm{QbD}$ principles on lyophilization process, first understanding of process is necessary [2].

The goal of this study was to demonstrate how statistical design of experiments (DoE) principles can efficiently screen and optimize formulation variables and identify the desired combination of variables within the design space for Sodium Fluoride.

Lyophilization is dehydration process by which the water is removed from a product. The term lyophilization is also called the freeze-drying process. The lyophilization process is widely used to dry the biological products which could not be stable at room temperature or extend the shelf life of product or make the material more convenient for transport. Lyophilization works by freezing the material then reducing the pressure and adding heat to allow the frozen water in material to sublimate [3].

\subsection{Advantages of Lyophilization}

Lyophilized products are multifold Lyophilized cakes, and have a high internal surface area which makes fast and complete reconstitution of the dried product possibly use in emergency medicine. It is much easier to achieve sterility assurance and freedom of particles than using other drying methods or handling of dry powders [4]. Pharmaceutical freeze-drying is not limited to products for parental and biological products use, but can also be used for e.g. fast dissolving tablets.

Nowadays the lyophilization is mostly used for the modification of the bulk properties such as flow properties, particle size and particle size distribution, so the present study is carried out for particle size reduction of sodium fluoride.

The process of lyophilization consists of three steps

- Freezing;

- Primary drying;

- Secondary drying.

For identifying the process variables, the process must be understood.

\subsection{Freezing}

First, the product solution is filled into container, mostly tray used on the temperature controlled shelves of the lyophilizer. The shelf temperature is reduced to a temperature between $-30^{\circ} \mathrm{C}$ to $-50^{\circ} \mathrm{C}$, resulting in formation of ice nuclei and subsequent growth of ice crystals after nucleation, the remaining solution is continuously concentrated until the maximally freeze-concentrated solute is obtained. At this point, both concentration and viscosity of the solution have substantially increased, resulting in an elastic amorphous state that is a discrete phase adjacent to the crystalline ice. The most important characteristic of this concentrated elastic solute phase is the temperature of transformation to a glassy state with substantially elevated rigidity and viscosity, the so-called glass transition temperature of the maximally freeze-concentrated solute, $\mathrm{Tg}$ ' [5]. The product temperature needs to be reduced below this temperature during the freezing step and maintained lower throughout the primary drying phase to prevent loss of the dried cake structure. If the solute is crystallizable, formation of a discrete crystalline solute phase may take place during the freezing or the drying phase [6]. In this case, the product temperature needs to be maintained below the eutectic temperature of the crystalline mixture, TE [7].

Upon completion of the freezing step, the solution is completely solidified, i.e. the most of water has been separated from the solute and is bound in ice crystals, and the solute has formed a glass or crystallized.

\subsection{Primary Drying}

After the freezing step has been completed, the pressure within the lyophilizer is reduced using a vacuum pump. Typical chamber pressures in the lyophilization of pharmaceuticals range from 0.200 to $1 \mathrm{mBar}$ and depend on 
the desired product temperature and the characteristics of the container system. The chamber pressure needs to be lower than the vapor pressure of ice at the sublimation interface in the product to start the sublimation of ice and transport of water vapor to the condenser where it is deposited as ice [8]. Very high chamber pressures decrease the sublimation rate by reducing the pressure gradient between sublimation interface and chamber, there by mitigating the driving force for sublimation and continuing removal of ice. If the chamber pressure exceeds the vapor pressure at the sublimation interface, no mass transfer is possible [9]. On the other hand, very low pressures $(<50 \mathrm{mBar})$ are also applied for fast sublimation rates since they greatly limit the rate of heat transfer to the product. The ice at the sublimation interface shows a vapor pressure that is directly correlated to the product temperature [10].

\subsection{Secondary Drying}

In the area where the ice has already been removed, desorption of water from the cake occurs; this process is called as secondary drying and already starts in the primary drying phase. Once all ice has been removed from all product containers, the shelf temperature is elevated and typically maintained at a temperature between $20^{\circ} \mathrm{C}$ and $40^{\circ} \mathrm{C}$ for several hours. The rate of desorption and the obtainable moisture level is controlled by diffusion within the solute phase and desorption from the surface and therefore depend mostly on product temperature; further reduction of chamber pressure is not required [11].

The ramp rate to the secondary drying temperature needs to be moderate $\left(0.1^{\circ} \mathrm{C} / \mathrm{min}\right.$ to $\left.0.3^{\circ} \mathrm{C} / \mathrm{min}\right)$ for amorphous substances to avoid surpassing the glass transition of the. Lyophilized cake and cake shrinkage Secondary drying times are usually designed to achieve a reduction of moisture content within the cake to less than $1 \%$. For most lyophilized API's the stability increases with the reduction of moisture, so it is beneficial to reduce the residual moisture as much as possible [12].

\subsection{Critical Variables Parameter of Lyophilization Cycle}

A critical parameter is defined as follows:

"A process control variable that: when operating beyond its acceptance range, has a major effect on Product safety or efficacy, or is likely to operate beyond a narrow range and have an impact on process consistency.”

Following are steps of lyophilization and critical parameters of it:

- Freezing

- RAMP

- Freezing temperature and time

- Annealing

- Primary drying

- RAMP

- Target product temperature

- Shelf temperature

- Primary drying end point

- Chamber pressure

- Secondary drying

- Heating rate

- Chamber pressure

- Shelf temperature

The critical factors affect the particle sizes of the product are explained by the ishikawa diagram which showing the root causes of the critical factors in that are the effect of the process variables, sample variables, instrumental variables or capability of instrument.

The ishikawa diagram (Figure 1) explains the root causes which will be helpful in controlling the variables. According to QbD approach the identification of root causes of variables play important role in the controlling the product quality.

Design of experiment is powerful tool for identifying the critical process parameter to optimize the respective condition. Critical factors in the lyophilization are optimized using Doe.

In present study we optimize the process parameters by using the Process analytical technology tool (PAT) [13]. The lyophilization cycle was optimized using the temperature sensors [14]. The temperature sensors are the 


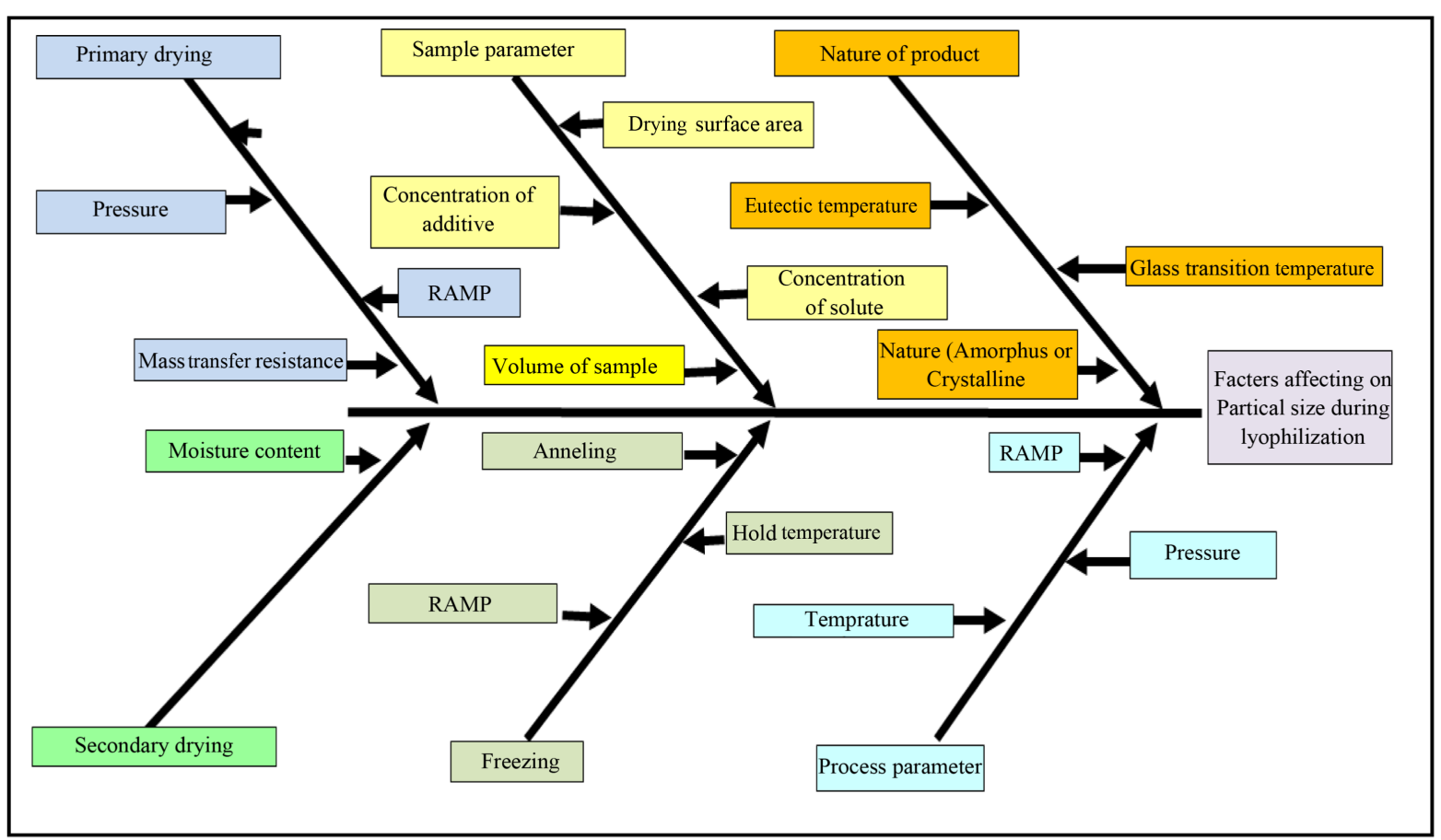

Figure 1. Ishikawa diagram for lyophilization.

inline tool for monitoring the temperature of product and shelf on basis of that the lyophilization cycle is optimized.

The $4^{3}$ full factorial design is applied to the product parameters to optimize the experimental condition for getting the minimum particle size. In that the 4 numerical parameter 1) Concentration of NaF, 2) Concentration of PVP, 3) Sample volume, 4) Drying surface area are taken. The 3 level designs were to make to study the influence on the particle size.

The presented work was carried out to establish a better understanding of factors influencing the particle size reduction effectiveness. The first objective is identification of influence of the variables on powder morphology and solid state characterization and another objective is to establish the process and product parameter to get smaller particle size. The particle size and the polydisparcity index were investigated as responses which describing the quality of product.

\section{Material and Methods}

\subsection{Materials}

API: Micronized sodium fluoride,

Additive: Polyvinylpyrrolidone,

Solvent: HPLC grade water,

Glassware: Petri plates of different surface area.

\subsection{Methods}

\subsubsection{Characterization of Sodium Fluoride}

For using the sodium fluoride as active pharmaceutical ingrident we carried out the following characterization

1) Nature,

2) Solubility,

3) Particle size.

\subsubsection{Fractional Factorial Screening Design}

A $4^{3}$ fractional factorial design (Table 1 ) was applied to evaluate the main effects of experiments, Concentration 
Table 1. Design levels.

\begin{tabular}{cccc}
\hline Variable & \multicolumn{2}{c}{ Level } & +1 \\
\hline Concentration of sodium fluoride, $\% \mathrm{w} / \mathrm{v}$ & -1 & 0 & $3 \% \mathrm{w} / \mathrm{v}$ \\
Concentration of PVP, $\% \mathrm{w} / \mathrm{v}$ & $1 \% \mathrm{w} / \mathrm{v}$ & $2 \% \mathrm{w} / \mathrm{v}$ & 2 \\
Volume of sample solution, $\mathrm{mL}$ & 0 & $20 \mathrm{~mL}$ & $30 \mathrm{~mL}$ \\
Drying surface area, $\mathrm{cm}^{2}$ & $10 \mathrm{~mL}$ & $79 \mathrm{~cm}^{2}$ & $143 \mathrm{~cm}^{2}$ \\
\hline
\end{tabular}

of sodium fluoride, Concentration of polyvinylpyrrolidone, Volume of sample solution, drying surface area [15]. Preliminary experiments were conducted to optimize the lyophilization drying cycle for Sodium fluoride.

And to establish a surface response model with respect to particle size and polydisparcity ratio.

\subsubsection{Confirmation of Design Space Experiments}

To confirm the formulation design space, four different variables and their low, center-points or high levels were selected. Sodium fluoride at those concentrations was analyzed and their observed responses studied. A desirability function was then applied based on the responses to obtain the optimum variables conditions to yield an optimum particle size with desired QTPP.

\subsubsection{Statistical Analyses}

All results were analyzed using the statistical software package Design-Expert ${ }^{\circledR}$ Software Version 8.

\subsubsection{Lyophilization}

For lyophilization the LABCONCO tray freeze dryer is used during this study.

Firstly the lyophilization cycle for the sodium fluoride is optimized using the temperature sensors, The API solution were prepared according to the factorial design at different concentration of API and Additive are made and kept that in tray dryer in different Petri plates and different volume according to the DoE.

\subsubsection{Particle Size Analysis by Laser Diffraction}

The laser diffraction study was performed with Delsa Nano particle analyzer (Beckman Coulter, Inc., CA, USA) to examine the particle size and particle size distribution of sodium fluoride. The sample was given directly in equipment with isopropyl alcohol as solvent.

\subsubsection{Characterization of Pre-Lyophilized and Lyophilized Formulations}

1) Appearance and reconstitution

The lyophilized formulations were visually inspected for cake appearance. The reconstitution time of the lyophilized cakes was determined by adding $5 \mathrm{~mL}$ of sterile water to the cakes and recording the time taken for the cake to dissolve into a clear solution. Samples were inspected post reconstitution for particulate matter, color and clarity.

\section{Result and Discussion}

Characterization of Sodium fluoride:

1) Nature: Crystalline,

2) Solubility: Water (3\%),

3) Particle size: 800 to $1000 \mathrm{~nm}$.

All prepared formulations were lyophilized to yield solid cakes. The lyophilization cycles consisted of three distinct stages; freezing, primary drying below the presumed glass transition temperature to remove the frozen water from the sample by sublimation, and secondary drying in which water was removed from the solute phase by desorption (Tang and Pikal, 2004). The application of Temperature sensor monitoring technology during lyophilization ensured that the primary drying endpoint predicted by product and shelf temperature measurement. 
The effectiveness of the lyophilization process was determined by visual inspection of the lyophilized products for cake appearance as well as reconstitution time of the product, clarity and absence of particulates in the reconstituted liquid. There was no visible shrinkage or macroscopic collapse of the cake structure (product quality criteria).

\subsection{Optimization of Lyophilization Cycle}

The lyophilization cycle (Figure 2) is optimized by using the temperature sensors [16]. The optimization is done on basis of the recording of shelf and product temperature. The monitoring or temperature gives the information about the temperature input and output of temperature.

\section{Lyophilization Cycle}

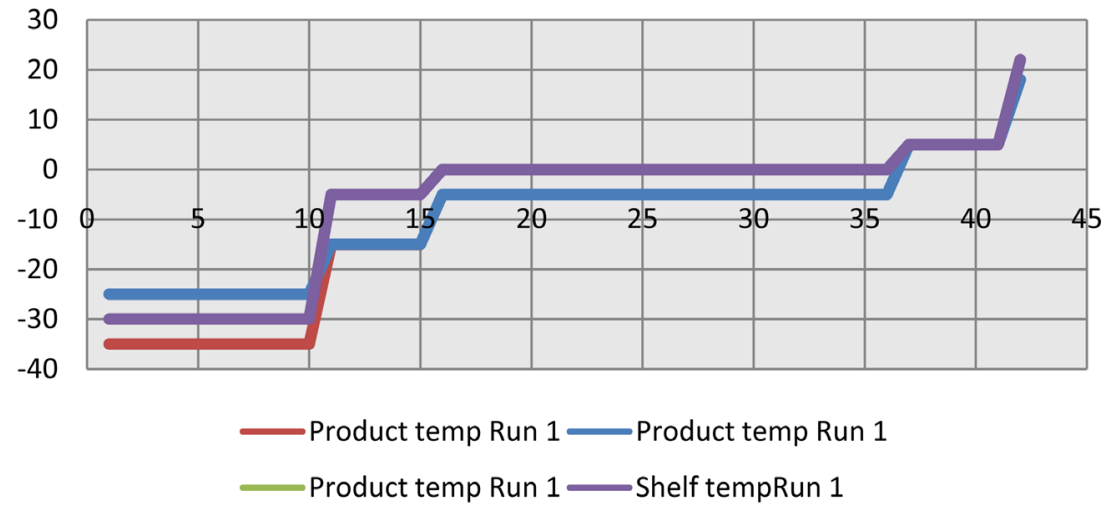

Figure 2. Graph of temperature vs. time for optimization of lyophilization cycle.

The above graph (Figure 2) explains that the temperature recording of trial runs. In that the run in which the product and shelf temperature are similar that run is selected for the experimental runs.

1) Data analysis

Factorial design

As the resolution of factorial design the two responses are recorded and the data is calculated by using the Design Expert (Table 2).

2) Design summary

Table 2. Doe design summary.

\begin{tabular}{cccc}
\hline Study Type & Factorial & Runs & 81 \\
\hline Initial Design & Full Factorial & Blocks & No Blocks \\
Design Model & $2 \mathrm{FI}$ & & \\
\hline
\end{tabular}

Response 1: Diameter

3) Model fit summary (Table 3)

Table 3. Table for fit summary.

\begin{tabular}{|c|c|c|c|c|c|c|}
\hline Source & Std. Dev. & R-Squared & Adj R-Squared & Pred R-Squared & PRESS & \\
\hline Linear & 824.28 & 0.317 & 0.281 & 0.216 & $5.93 \mathrm{E}+07$ & \\
\hline $2 \mathrm{FI}$ & 780.02 & 0.437 & 0.356 & 0.228 & $5.84 \mathrm{E}+07$ & \\
\hline Quadratic & 663.56 & 0.616 & 0.5346 & 0.400 & $4.54 \mathrm{E}+07$ & Suggested \\
\hline Cubic & 599.55 & 0.762 & 0.62 & 0.285 & $5.41 \mathrm{E}+07$ & Aliased \\
\hline
\end{tabular}

ANOVA: The Model F-value of 7.56 implies the model is significant. There is only a $0.01 \%$ chance that a "Model F-Value" this large could occur due to noise. 
After calculation of data the following result are obtained (Table 4).

Table 4. Table for statistical data.

\begin{tabular}{cccc}
\hline Std. Dev. & 663.56 & R-Squared & 0.616 \\
Mean & 1277.11 & Adj R-Squared & 0.5346 \\
C.V. $\%$ & 51.96 & Pred R-Squared & 0.4001 \\
PRESS & $4.54 \mathrm{E}+07$ & Adeq Precision & 10.843 \\
\hline
\end{tabular}

4) Final equation in terms of actual factors: for diameter

Diameter $=2314.51861-252.23768 *$ Concentration $-2158.77276 *$ PVP concentration $-74.76847 *$ Volume $-0.36216 *$ Surface area $+270.30278 *$ Concentration * PVP concentration $+7.90028 *$ Concentration * Volume $-1.69055 *$ Concentration * Surface area $-37.23083 *$ PVP concentration * Volume $+2.81577 *$ PVP concentration $*$ Surface area $-0.06131 *$ Volume $^{*}$ Surface area $+57.97222 *$ Concentration $^{2}+800.78889 *$ PVP concentration ${ }^{2}+3.26894 *$ Volume $^{2}+6.28 \mathrm{E}-03 *$ Surface $^{2}$ area $^{2}$

5) $3 \mathrm{D}$ response obtained for diameter (Figure 3)

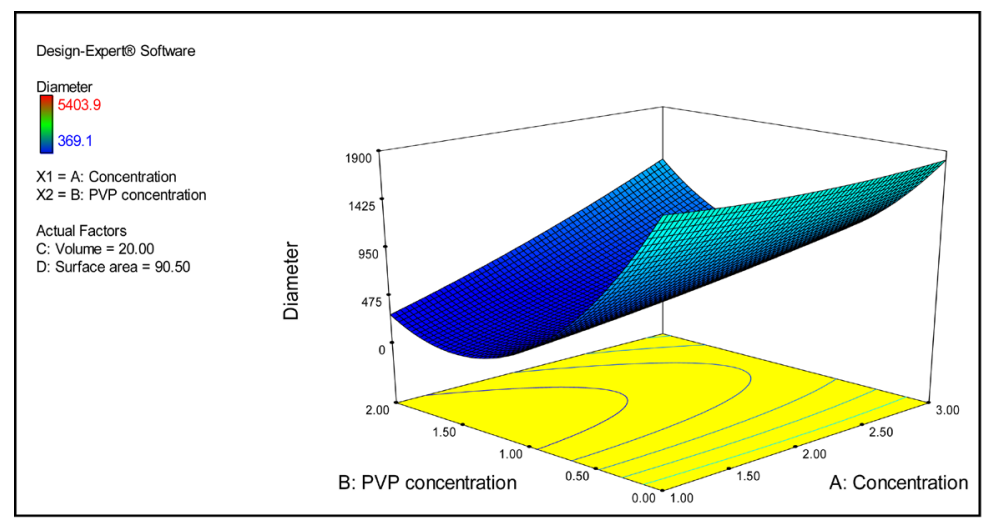

Figure 3. Graph for 3D surface.

6) Response 2: PDI (Table 5)

Table 5. Model summary statistics.

\begin{tabular}{cccccc}
\hline Source & $\begin{array}{c}\text { Std. } \\
\text { Dev. }\end{array}$ & R-Squared & $\begin{array}{c}\text { Adj } \\
\text { R-Squared }\end{array}$ & $\begin{array}{c}\text { Pred } \\
\text { R-Squared }\end{array}$ & PRESS \\
\hline Linear & 1.098 & 0.203 & 0.161 & 0.0682 & 107.263 \\
2FI & 1.075 & 0.297 & 0.196 & -0.072 & 123.477 \\
Quadratic & 1.045 & 0.373 & 0.240 & -0.046 & 120.495 \\
Cubic & 0.971 & 0.590 & 0.344 & -0.312 & 151.143 \\
\hline
\end{tabular}

7) ANOVA for PDI

The Model F-value of 2.81 implies the model is significant. There is only a $0.25 \%$ chance that a "Model F-Value” this large could occur due to noise.

Values of "Prob > F" less than 0.0500 indicate model terms are significant. In this case B, AB, B ${ }^{2}$ are significant model terms. Values greater than 0.1000 indicate the model terms are not significant.

After calculation of data the following result are obtained.

Statistical data for PDI (Table 6)

Table 6. Statistical data for PDI.

\begin{tabular}{cccc} 
Std. Dev. & 1.045 & R-Squared & 0.373 \\
Mean & 0.786 & Adj R-Squared & 0.240 \\
C.V. \% & 133.031 & Pred R-Squared & -0.046 \\
PRESS & 120.495 & Adeq Precision & 7.102 \\
\hline
\end{tabular}


8) Final equation in terms of actual factors: for PDI

PDI $=6.330076-1.7099 *$ Concentration $-2.46014 *$ PVP concentration $-0.11796 *$ Volume $-0.04396 *$ Surface area $+0.366278 *$ Concentration $*$ PVP concentration $+0.006939 *$ Concentration * Volume + $0.003833 *$ Concentration * Surface area $-0.01878 *$ PVP concentration * Volume $+0.004999 *$ PVP concen-

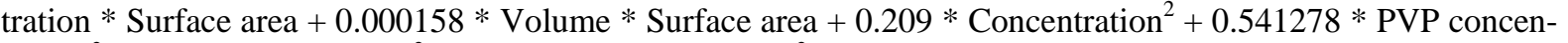
tration $^{2}+0.002928 *$ Volume $^{2}+0.000129 *$ Surface $^{2}$ area $^{2}$

9) 3D surface for PDI (Figure 4)

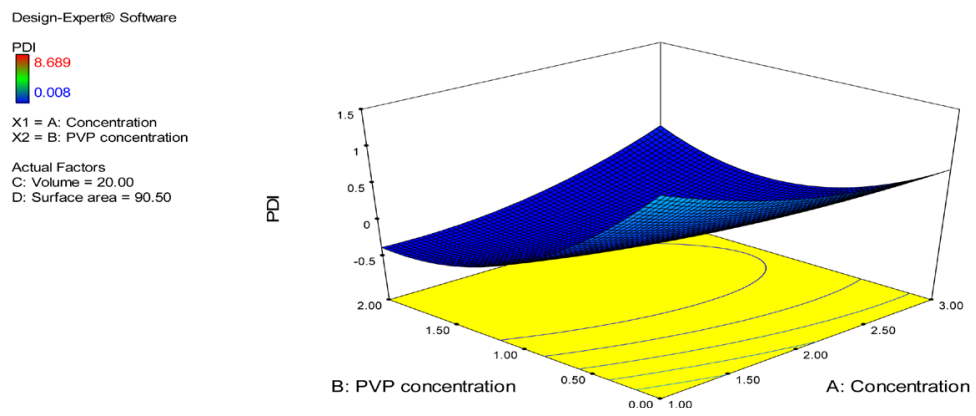

Figure 4. 3D surface for PDI.

\subsubsection{Numerical Optimization}

Numerical optimization gives correlation of optimized results with respect to Concentration of Active material, concentration of PVP, Volume of solution used in lyophilization and Surface area exposed to drying process. The optimization gives guideline to design the experiment for obtaining the significant results with respect to particle size and polydispersity ratio (Table 7).

Table 7. Table for numerical optimization.

\begin{tabular}{|c|c|c|c|c|c|c|}
\hline $\begin{array}{c}\text { Constraints } \\
\text { Name }\end{array}$ & Goal & $\begin{array}{l}\text { Lower } \\
\text { Limit }\end{array}$ & $\begin{array}{l}\text { Upper } \\
\text { Limit }\end{array}$ & $\begin{array}{l}\text { Lower } \\
\text { Weight }\end{array}$ & $\begin{array}{c}\text { Upper } \\
\text { Weight }\end{array}$ & Importance \\
\hline Concentration & is in range & 1 & 3 & 1 & 1 & 3 \\
\hline PVP concentration & is in range & 0 & 2 & 1 & 1 & 3 \\
\hline Volume & is in range & 10 & 30 & 1 & 1 & 3 \\
\hline Surface area & is in range & 38 & 143 & 1 & 1 & 3 \\
\hline Diameter & is in range & 369.1 & 1000 & 1 & 1 & 3 \\
\hline PDI & is in range & 0.008 & 0.299 & 1 & 1 & 3 \\
\hline
\end{tabular}

\subsubsection{Graphical Optimization}

It shows the optimization for the particles size and polydispersity ratio (Figure 5).

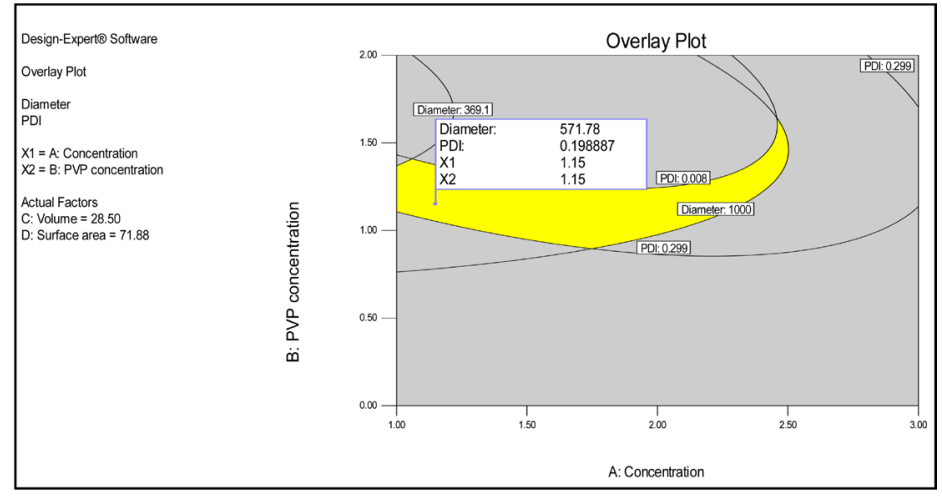

Figure 5. Overlay plot. 


\section{Conclusions}

The experiment shows significant effect on the particle size and polydispersity ratio of the sodium fluoride. Variables in experiment show a great influence on the particle size and PDI. The influence of factor 1 concentration of sodium fluoride is effect on particle size at lowest level as the minimum concentration of sodium fluoride i.e. the minimum amount of solute on the sample shows reduced partial size; the factor 2 concentration of PVP is effect on the particle growth of the sodium fluoride at level below $1 \%$, at which the particle size is reduced, as the PVP has binder in nature; the concentration is affective at minimum level.

The factor 3 sample volume shows effect on particle size at the volume range of $15 \mathrm{~mL}$ - $20 \mathrm{~mL}$ that will be changed according to the capacity of the glassware. The factor 4 drying surface area shows effect at area of drying surface in the range of sample volume; the drying area affects the particle size by resistance to mass transfer ratio to the water vapors.

The graphical (Figures 3-5) and numerical optimization (Tables 3-7) shows that all factors are in range and the graphical optimization shows the investigation of design space for particle size reduction in lyophilization.

Concentration of Sodium fluoride:

The variable concentration of solute affects the particle size at the freezing step of lyophilization process. In freezing step, the sample is freezing and the solute and solvent present in sample are separated in that phase. Both are in the same phase i.e. in solids phase that they create pressure during the ice nucleation process [17]. The growth of the particle size during freezing is affected by the concentration of solute in solvent.

The quantity of solute affects the rate of evaporation by more mass resistance transfer rate.

1) Concentration of PVP

The additives are necessary to use in the lyophilization process for stabilizing the sodium fluoride because the sodium fluoride is crystalline in nature and during the lyophilization process the crystalline nature affects the particle size growth. The PVP achieves the reduction in particle size by the surface modification [18].

2) Volume of sample

The volume of sample affects on the rate of drying, as the more the volume of sample, the slower the rate of mass transfer.

3) Drying surface area

The drying surface area affects the particle size of the sodium fluoride, as the more the drying surface area exposed to the process, the slower the rate of freezing and drying affected.

\section{Acknowledgements}

Authors are thankful to ICPA Health Products LTD, Ankleshwar, INDIA for providing the facility of Lyophilization and materials required for the experiment authors also thankful Dr. R. B. Navale (Government College of Pharmacy, Aurangabd) for guiding in the Particle size analysis.

\section{References}

[1] ICH (2007) Pharmaceutical Quality System. International Conference on Harmonization (ICH) Q10, Geneva, 2007. http://www.fda.gov/downloads/Drugs/.../Guidances/ucm073517.pdf

[2] Jameel, F. and Khan, M. (2009) Quality-by-Design as Applied to the Development and Manufacturing of a Lyophilized Protein Product. American Pharmaceutical Review, 20-24.

[3] Tang, X. and Pikal, M.J. (2004) Design of Freeze-Drying Processes for Pharmaceuticals: Practical Advice. Pharmaceutical Research, 21, 191-200. http://dx.doi.org/10.1023/B:PHAM.0000016234.73023.75

[4] Nail, S.L., Jiang, S., Chongprasert, S. and Knopp, S.A. (2002) Fundamentals of Freeze Drying. Pharmaceutical Biotechnology, 14, 281-360. http://dx.doi.org/10.1007/978-1-4615-0549-5_6

[5] Franks, F. (1992) Freeze-Drying: From Empiricism to Predictability. The Significance of Glass Transitions. Developments in Biological Standardization, 74, 9-18.

[6] Korey, D.J. and Schwartz, J.B. (1989) Effects of Excipients on the Crystallization of Pharmaceutical Compounds during Lyophilization. Journal of Pharmaceutical Science and Technology, 43, 80-83.

[7] Gatlin, L.A. and Nail, S.L. (1994) Protein Purification Process Engineering. Freeze Drying: A Practical Overview. Bioprocess Technology, 18, 317-367.

[8] Barresi, A.A., Pisano, R., Fissore, D., Rasetto, V., Velardi, S.A., Vallan, A., Parvis, M. and Galan, M. (2009) Monitor- 
ing of the Primary Drying of a Lyophilization Process in Vials. Chemical Engineering and Processing, 48, 408-423. http://dx.doi.org/10.1016/j.cep.2008.05.004

[9] Sadikoglu, H., Ozdemir, M. and Seker, M. (2003) Optimal Control of the Primary Drying Stage of Freeze Drying of Solutions in Vials Using Variationl Calculus. Drying Technology, 21, 1307-1331. http://dx.doi.org/10.1081/DRT-120023182

[10] Wagner, W., Saul, A. and Pruss, A. (1994) International Equations for the Pressure along the Melting and along the Sublimation Curve of Ordinary Water Substance. Journal of Physical and Chemical Reference Data, 23, 515-517. http://dx.doi.org/10.1063/1.555947

[11] Pikal, M.J., Shah, S., Roy, M.L. and Putman, R. (1990) The Secondary Drying Stage of Freeze Drying Kinetics as a Function of Temperature and Chamber Pressure. International Journal of Pharmaceutics, 60, 203-207. http://dx.doi.org/10.1016/0378-5173(90)90074-E

[12] Pikal, M.J. and Shah, S. (1997) Intravial Distribution of Moisture during the Secondary Drying Stage of Freeze Drying. PDA Journal of Pharmaceutical Science and Technology, 51, 17-24.

[13] De Beer, T.R., Alles, O.M., Goethals, F., Coppens, A., Vander Heyden, Y., Lopez De Diego, H., Rantanen, J., Verpoort, F., Vervaet, C., Remon, J.P. and Baeyens, W.R.G. (2007) Implementation of a Process Analytical Technology System in a Freeze-Drying Process Using Raman Spectroscopy for In-Line Process Monitoring. Analytical Chemistry, 79, 7992-8003. http://dx.doi.org/10.1021/ac070549h

[14] Tang, X.C., Nail, S.L. and Pikal, M.J. (2006) Evaluation of Manometric Temperature Mea-Surement, a Process Analytical Tool for Freeze-Drying. Part I: Product Temperature Measurement. AAPS PharmSciTech, 7, E14.

[15] van de Ven, P., Bijlsma, S., Gout, E., van der Voort Maarschalk, K. and Thissen, U. (2011) A Frame Work for Efficient Process Development Using Optimal Experimental Designs. Journal of Pharmaceutical Innovation, 6, 24-31. http://dx.doi.org/10.1007/s12247-011-9098-2

[16] Gieseler, H. (2007) PAT for Freeze Drying: Cycle Optimization in the Laboratory. European Pharmaceutical Review, 7, 62-67.

[17] Kasper, J.C. and Friess, W. (2011) The Freezing Step in Lyophilization: Physico-Chemical Fundamentals, Freezing Methods and Consequences on Process Performance and Quality Attributes of Biopharmaceuticals. European Journal of Pharmaceutics and Biopharmaceutics, 78, 248-263. http://dx.doi.org/10.1016/j.ejpb.2011.03.010

[18] Kenneth, C. (1994) Cundy Method to Reduce Particle Size Growth during Lyophilization. Patent US5302401. 